neglecting to valuing differences in personality can benefit interactions and generate more options and possibilities. Applying these principles to an appraisal process involves adapting to meet the appraisees' individual needs. Personality Type training should therefore assist in generating richer discussions, higher levels of interest in immediate and future outcomes, and energise the process for all parties.

\section{CONCLUSION}

Peer appraisal is perceived to be the 'cement', which binds the system for the revalidation of doctors, who wish to be licensed to practice in the UK. Appraisers need to acquire the requisite skills to ensure that doctors engage fully and honestly in the appraisal and revalidation processes. In order to fulfil this requirement, training to enable an understanding of personality and how it influences the outcome of appraisal is essential for peer appraisal.

\section{Jill Murie}

\section{Acknowledgements}

The author wishes to thank Georgia Barr Consulting Ltd for facilitating GP appraiser training in NHS Lanarkshire and the Scottish GP National Appraiser conference and Diane Kelly, Assistant Director, NHS Education for Scotland for advice and support.

\section{REFERENCES}

1. Law S, Haman H, Cameron N, Staples I. GP peer appraisal in Scotland: an ongoing and developing exercise in quality. Education for Primary Care 2009; 20: 99-103.

2. Myers IB, McCaullet MH, Quenk NL, Hammer AL. Manual: a guide to the development and use of the Myers-Briggs type indicator. 3rd edn. Palo Alto, CA: Consulting Psychologists Press, 1998.

DOI: 10.3399/bjgp10X502001

\title{
There's no such thing as flexible training for GP trainees
}

It was my own fault for falling in love with a fellow medical student and marrying her 2 days after we graduated. Apart from never doing nights at the same time, our first Foundation Year worked out rather well. Then there was the small matter of the arrival of a new baby in Foundation Year 2.

Becky returned to work full-time as a Foundation Year 2 doctor while I was an StR1 on a GP vocational training scheme. As a result of busy jobs with long hours our daughter spent more of her waking hours in nursery than with us. We would swap our on-calls to make sure they didn't clash and so someone was free to collect her from nursery.

We therefore decided that I would work less than full-time (LTFT) and look after our daughter, with the help of our extended family. Becky was keen to get through her hospital jobs speedily to train as a GP as well.

Any notion I had about the flexibility of LTFT training soon disappeared. Every 8 months I changed jobs and worked on different days of the week in different placements. Furthermore, I would usually swap the days of the week I worked half way through the post, to make sure I wasn't missing out on learning opportunities. It is impossible to chop and change the days your child spends at a popular nursery.

So for the last year or so we've used a mixture of nursery and help from extended family to provide care for our daughter. Paying for nursery 5 days a week to keep our options open for changing working days of the week was not an attractive option when my salary had been chopped.

Choosing to work as an LTFT trainee is one of the best career decisions I have made. It's given me the opportunity to see more of my children as they grow up and to not merely survive, but thrive and learn in my hospital posts. However, one thing I have realised is that in my experience, LTFT is certainly not flexible.

'Nobody on his deathbed ever said, "I wish I had spent more time at the office".' Senator Paul Tsongas (1941-1997)

\section{Samir Dawlatly}

DOI: 10.3399/bjgp10X502010 